\title{
Role of Controlled Cardiac Reoxygenation in Reducing Nitric Oxide Production and Cardiac Oxidant Damage in Cyanotic Infantile Hearts
}

\author{
Kiyozo Morita, * Kai Ihnken, " Gerald D. Buckberg, * Michael P. Sherman, * Helen H. Young, * and Louis J. Ignarro" \\ * Division of Cardiothoracic Surgery, Department of Surgery, ${ }^{*}$ Division of Neonatology, Department of Pediatrics, Department of \\ Pharmacology, School of Medicine University of California, Los Angeles, California 90024
}

\begin{abstract}
Cardiopulmonary bypass (CPB) is used increasingly to correct cyanotic heart defects during early infancy, but myocardial dysfunction is often seen after surgical repair. This study evaluates whether starting CPB at a conventional, hyperoxic $\mathrm{pO}_{2}$ causes an "unintentional" reoxygenation $\left(\mathrm{ReO}_{2}\right)$ injury. We subjected 2-wk-old piglets to ventilator hypoxemia $\left(\mathrm{FIO}_{2} \sim 0.06, \mathrm{pO}_{2}\right.$ $\sim 25 \mathrm{mmHg}$ ) followed by $5 \mathrm{~min}$ of $\mathrm{ReO}_{2}$ on CPB before instituting cardioplegia. CPB was begun in hypoxemic piglets by either abrupt $\mathrm{ReO}_{2}$ at a $\mathrm{pO}_{2}$ of $\mathbf{4 0 0} \mathbf{m m H g}$ (standard clinical practice) or by maintaining $\mathrm{pO}_{2} \sim 25 \mathrm{mmHg}$ on CPB until controlling $\mathrm{ReO}_{2}$ with blood cardioplegic arrest. The effects of abrupt vs. gradual $\mathrm{ReO}_{2}$ without surgical ischemia (blood cardioplegia) were also compared. Myocardial nitric oxide (NO) production (chemiluminescence measurements of $\mathrm{NO}_{2}^{-}$ $+\mathrm{NO}_{3}^{-}$) and conjugated diene (CD) generation (spectrophotometric $\mathbf{A}_{233}$ measurements of lipid extracts) using aortic and coronary sinus blood samples were assessed during cardioplegic induction. $30 \mathrm{~min}$ after CPB, left ventricular end-systolic elastance (Ees, catheter conductance method) was used to determine cardiac function. CPB and blood cardioplegic arrest caused no functional or biochemical change in normoxic (control) hearts. Abrupt $\mathrm{ReO}_{2}$ caused a depression of myocardial function ( $E$ es $=25 \pm 5 \%$ of control ). Functional depression was relatively unaffected by gradual $\mathrm{ReO}_{2}$ without blood cardioplegia (34\% recovery of Ees), and abrupt $\mathrm{ReO}_{2}$ immediately before blood cardioplegia caused a 10-fold rise in cardiac NO and CD production, with subsequent depression of myocardial function (Ees $21 \pm 2 \%$ of control). In contrast, controlled cardiac $\mathrm{ReO}_{2}$ reduced NO production $94 \%, \mathrm{CD}$ did not rise, and Ees was $83 \pm 8 \%$ of normal. We conclude $\mathrm{ReO}_{2}$ injury is related to increased $\mathrm{NO}$ production during abrupt $\mathrm{ReO}_{2}$, nullifies the cardioprotective effects of blood cardioplegia, and that controlled cardiac $\mathrm{ReO}_{2}$ when starting CPB to correct cyanotic heart defects may reduce NO production and improve myocardial status postoperatively. (J. Clin. Invest. 93:2658-2666.) Key words: reoxygenation injury $\cdot$ cardiopulmonary bypass $\cdot$ cyanotic heart disease $\cdot$ nitric oxide $\cdot$ oxidant damage
\end{abstract}

Address correspondence to Gerald D. Buckberg, M.D., UCLA Medical Center, Department of Surgery, Room B2-375 CHS, Los Angeles, CA 90024-1741.

Received for publication 7 September 1993 and in revised form 27 December 1993.

J. Clin. Invest.

(c) The American Society for Clinical Investigation, Inc.

$0021-9738 / 94 / 06 / 2658 / 09 \$ 2.00$

Volume 93, June 1994, 2658-2666

\section{Introduction}

Repair of heart defects causing cyanosis is performed on cardiopulmonary bypass $(\mathrm{CPB})^{1}$ in early infancy with increasing frequency. Postoperative cardiac dysfunction is the major cause of morbidity and mortality despite successful surgical correction and is more common in infants than in adult cardiac patients (29). The conventional method of starting CPB in hypoxemic infants is to raise $\mathrm{pO}_{2}$ to $>400 \mathrm{mmHg}$ by mixing their blood with fluid in the extracorporeal circuit pre-circulated at hyperoxic levels. We have speculated that such abrupt reoxygenation causes an "unintended reoxygenation injury" $(2)$ and adds to subsequent intraoperative oxidative stress due to surgical ischemia that provides a bloodless field, and limits the effectiveness of a cardioplegic strategy shown previously to reduce reperfusion damage $(3,4)$. Our hypothesis is based on experimental evidence that cyanosis reduces endogenous myocardial antioxidants and reoxygenation enhances free radical generation (5). In support of this hypothesis, clinical reports show myocardial lipid peroxidation in pre-ischemic biopsies from cyanotic children (6), cardioplegic protection is less adequate in cyanotic versus normoxic patients despite shorter ischemic intervals (7) and myocardial dysfunction in cyanotic infants placed on extracorporeal membrane oxygenation (ECMO) despite absence of surgical ischemia $(8,9)$.

Studies indicate reactive oxygen species mediate reperfusion/reoxygenation injury (10) via the classic Haber-Weiss (Fenton) pathway (11). An alternate mechanism of oxidant injury was proposed recently by Beckman et al.(4), whereby superoxide anion $\left(\mathrm{O}_{2}^{-}\right)$and nitric oxide (NO) interact to form cytotoxic $\mathrm{O}_{2}$ species (12). We showed recently cyanotic infantile hearts reoxygenated on CPB have a burst of NO which was associated with oxidant damage and myocardial dysfunction which could be ameliorated by either adding a NO synthase (NOS) inhibitor or antioxidants to the priming solution of the CPB circuit (2). Unfortunately, NOS inhibition with a L-arginine analog produced severe systemic vasoconstriction and resulted in pancreatic damage despite its cardioprotective effect and the antioxidants added to the CPB prime are not available clinically.

Alternative strategies do, however, exist during conventional cardiac operations that can reduce $\mathrm{NO}$ and $\mathrm{O}_{2}^{-}$production. For example, generation of $\mathrm{O}_{2}^{-}$and $\mathrm{NO}$ is $\mathrm{pO}_{2}$ dependent $(13,14)$, and controlling the rate of reintroduction of molecular oxygen when CPB is started and cardioplegic solution is administered may avoid the burst of $\mathrm{NO}$ and $\mathrm{O}_{2}^{-}$that follows

1. Abbreviations used in this paper: $\mathrm{BCP}$ : blood cardioplegia; CPB, cardiopulmonary bypass; Ees, end-systolic elastance; NO, nitric oxide; $\mathrm{ReO}_{2}$, reoxygenation. 
abrupt reoxygenation $(2,15)$. Furthermore, NO production is limited also by several aspects of a cardioplegic strategy developed for avoiding reperfusion injury $(3,4)$ and used clinically (16). These include making the cardioplegic solution hypocalcemic and alkalotic to reduce calcium/calmodulin- and $\mathrm{pH}$ dependent constitutive NOS activation $(17,18)$, supplementing cardioplegic solution with glutamate/aspartate that may reduce NO synthesis by inhibiting L-arginine transport (1921 ) and gentle cardioplegic delivery pressure to limit sheer stress and decrease endothelial NO production (22). This study tests whether abrupt reoxygenation of cyanotic hearts during initiation of conventional CPB at high $\mathrm{pO}_{2}$ produces a reoxygenation injury that is $(a)$ reduced only minimally by gradual reoxygenation alone, and $(b)$ mitigated by delaying reoxygenation until blood cardioplegia is given. We called this latter treatment, controlled cardiac reoxygenation.

\section{Methods}

The experimental model and protocols used in this study were approved by the Chancellors Research Committee of the University of California, Los Angeles and meet the standards of the National Institutes of Health.

\section{Experimental model}

40 immature, 2-wk-old Yorkshire Duroc piglets (4-6 kg) were premedicated with $0.5 \mathrm{mg} / \mathrm{kg}$ diazepam intramuscularly, anesthetized with $30 \mathrm{mg} / \mathrm{kg}$ pentobarbital intraperitoneally, followed by $5 \mathrm{mg} / \mathrm{kg}$ intravenously each hour and ventilated on a volume limited respirator (Servo 900D; Siemens-Elema, Sweden ) via a tracheostomy. The ductus arteriosus was occluded with a surgical clip via a left thoracotomy and the coronary sinus was cannulated for blood sampling via the ligated hemiazygous vein. The heart was exposed by median sternotomy, and transducer tip catheters (Millar Instruments, Inc., Kankakee, II) were placed into the left ventricle, thoracic aorta, left atrium, and right atrium and pulmonary artery. The signals were routed to a recorder (MT 9000; Astro-Med Inc, West Warwick, RI) via signal conditioners (model 13-4615; Gould Inc, Glen Burnie, MD). A thermodilution probe (No. 4) was directed into the main pulmonary artery and connected to a cardiac output computer (model 9520A; American Edwards Laboratory, Santa Ana, CA). An eight-electrode-equipped conductance catheter (Webster Laboratories, Baldwin Park, CA) was inserted through the left ventricular apex and connected to a Sigma-5-DF signal conditioner processor (Leycom, Netherlands).

After systemic heparinization $(3 \mathrm{mg} / \mathrm{kg})$, a thin-walled venous cannula (No. $20 \mathrm{Fr}$ ) and an aortic cannula (No. $8 \mathrm{Fr}$ ) were inserted into the right atrial appendage and the left subclavian artery. A 16gauge Teflon needle was placed into the proximal aorta to deliver cardioplegia and monitor aortic root pressure during cardioplegic delivery. Arterial blood gases, electrolytes, and hemoglobin measurements (Blood Gas System 228; Ciba-Corning, Medfield, MA) were measured to ensure optimum extracorporeal circulation, and a heating pad was placed to keep rectal temperature at $38^{\circ} \mathrm{C}$. The CPB circuit was heparinized, primed with packed red cells from donor pigs, and made normocalcemic with $\mathrm{CaCl}_{2}$. Hematocrit was adjusted to $25-30 \%$ with $\mathrm{He}-$ tastarch (Hespan, Dupont, Wilmington, DE) and plasma-electrolyte solution (Baxter Healthcare, Deerfield, IL). A Sarns 16310 Membrane oxygenator (Sarns, Ann Arbor, MI) was used, and aortic pressure kept at $50-60 \mathrm{mmHg}$ by adjusting systemic flow to $\sim 100 \mathrm{ml} / \mathrm{kg} / \mathrm{min}$. The left ventricle was decompressed by a vent placed through an apical stab wound.

\section{Experimental protocols}

\section{CONTROL}

Instrumentation without $C P B$. Five normoxic piglets $\left(\mathrm{pO}_{2} \sim 100-150\right.$ $\mathrm{mmHg}$ ) were anesthetized, cannulated for CPB, and observed over $5 \mathrm{~h}$ to provide control hemodynamic and biochemical data, since the hypoxia/reoxygenation studies (see below) had this duration.

Blood cardioplegia without hypoxemia. To test the safety of our blood cardioplegic protocol during surgical ischemia in immature hearts, six normoxic piglets ( $\mathrm{pO}_{2} \sim 100 \mathrm{mmHg}$ ) underwent $60 \mathrm{~min}$ of $\mathrm{CPB}$ at $\mathrm{pO}_{2} 400 \mathrm{mmHg}$ without preceding hypoxemia. After $5 \mathrm{~min}$ of $\mathrm{CPB}$, they underwent $30 \mathrm{~min}$ of aortic clamping with $\mathrm{pO}_{2} 400 \mathrm{mmHg}$ blood cardioplegia. The cardioplegic formulation, as described in Table I, was developed experimentally (3), and is used clinically (23). The blood cardioplegic protocol included warm cardioplegia $\left(37^{\circ} \mathrm{C}\right)$ for $3 \mathrm{~min}$ followed by cold cardioplegia for $2 \mathrm{~min}\left(4^{\circ} \mathrm{C}\right)$, and a 3-min infusion of $37^{\circ} \mathrm{C}$ blood cardioplegia just before aortic unclamping. Infusion rate was regulated by calibrated roller pump at $10 \mathrm{ml} / \mathrm{kg} / \mathrm{min}$ initially to produce arrest and $5 \mathrm{ml} / \mathrm{kg} / \mathrm{min}$ thereafter with aortic pressure averaging $\sim 50 \mathrm{mmHg}$.

\section{HYPOXIA/REOXYGENATION MODEL}

29 piglets were made hypoxic by lowering inspired $\mathrm{O}_{2}$ to $6-7 \%$ to reduce $\mathrm{pO}_{2}$ to $\sim 25 \mathrm{mmHg}$ for up to 120 min before reoxygenation on $\mathrm{CPB}$ for $60 \mathrm{~min}$. Extracorporeal circulation was begun before $120 \mathrm{mins}$ if mean arterial pressure fell below $30 \mathrm{mmHg}$ and/or arterial $\mathrm{pH}$ could not be kept above 7.35 by infusing $\mathrm{NaHCO}_{3}(1 \mathrm{mEq} / \mathrm{kg})$ by bolus injections.

\section{Hypoxia/reoxygenation without surgical ischemia}

Abrupt reoxygenation. Five piglets were reoxygenated by the conventional clinical procedure of starting CPB at $\mathrm{pO}_{2} \sim 400 \mathrm{mmHg}$. CPB was maintained for $60 \mathrm{~min}$ without aortic clamping.

Gradual reoxygenation. In five piglets, the CPB circuit was primed with blood at $\mathrm{pO}_{2} \sim 25 \mathrm{mmHg}$ achieved by blending nitrogen and oxygen. The $\mathrm{pO}_{2}$ was kept at $\sim 25 \mathrm{mmHg}$ for the first $5 \mathrm{~min}$ of $\mathrm{CPB}$, raised to $100 \mathrm{mmHg}$ for the next $30 \mathrm{~min}$, then to $400 \mathrm{mmHg}$ over the last $25 \mathrm{~min}$ of CPB. The aorta was not clamped.

\section{Hypoxia/reoxygenation with surgical ischemia}

19 hypoxic piglets were placed on $\mathrm{CPB}$ using either a hyperoxic $\left(\mathrm{pO}_{2}\right.$ $\sim 400 \mathrm{mmHg}$ ), normoxic $\left(\mathrm{pO}_{2} \sim 100 \mathrm{mmHg}\right)$, or hypoxic $\left(\mathrm{pO}_{2} \sim 25\right.$ $\mathrm{mmHg}$ ) prime in the CPB circuit. After $5 \mathrm{~min}$ of $\mathrm{CPB}$, all piglets underwent 30 min of aortic clamping using the blood cardioplegia regimen described previously, followed by 25 min of reperfusion before discontinuing bypass. The $\mathrm{CPB}$ and blood cardioplegic $\mathrm{pO}_{2}$ were adjusted as follows.

Initial hyperoxic $C P B$. Eight piglets underwent conventional reoxygenation on $\mathrm{CPB}$ at $\mathrm{pO}_{2} \sim 400 \mathrm{mmHg}$. After $5 \mathrm{~min}$, the aorta was clamped and blood cardioplegia was delivered at $\mathrm{pO}_{2} \sim 400 \mathrm{mmHg}$.

Initial normoxic $C P B$. In five piglets, $\mathrm{CPB}$ was started normoxically at $\mathrm{pO}_{2} \sim 100 \mathrm{mmHg}$, and normoxic blood cardioplegia was delivered 5 min later. $\mathrm{CPB} \mathrm{pO}_{2}$ was raised to $400 \mathrm{mmHg}$ after aortic unclamping.

Initial hypoxic $C P B$. In six piglets, $\mathrm{CPB}$ was started at the ambient hypoxic $\mathrm{pO}_{2}$ ( $\sim 25 \mathrm{mmHg}$ during ventilator hypoxemia $)$. Initial CPB

\section{Table I. Blood Cardioplegia Formulation}

\begin{tabular}{|c|c|c|}
\hline Principle & Constituent & Final concentration \\
\hline Deliver oxygen & Blood & Hematocrit $20-24 \%$ \\
\hline Maintain arrest & $\mathrm{KCL}$ & $\begin{array}{l}18-20 \mathrm{mEq} / \mathrm{l} \text { (induction) } \\
10-12 \mathrm{mEq} / 1 \text { (reperfusion) }\end{array}$ \\
\hline Buffer acidosis & THAM & pH 7.6-7.7 \\
\hline Avoid edema & Glucose & Osmolarity $380-400 \mathrm{mOsm}$ \\
\hline Restore substrate & $\begin{array}{l}\text { Glutamate } \\
\text { Aspartate }\end{array}$ & $13 \mathrm{mmol} / \mathrm{l}$ \\
\hline Limit calcium influx & $\begin{array}{l}\text { Glucose } \\
\text { CPD }\end{array}$ & $\begin{array}{l}>400 \mathrm{mg} / \mathrm{dl} \\
\left(\mathrm{Ca}^{2+}\right) 0.2-0.3 \mathrm{mmol} / \mathrm{l}\end{array}$ \\
\hline
\end{tabular}


flow was increased $50 \%$ during these $5 \mathrm{~min}$ (to $150 \mathrm{ml} / \mathrm{kg}$ ) to augment tissue $\mathrm{O}_{2}$ delivery. Systemic and cardiac reoxygenation was delayed until blood cardioplegia was given; $\mathrm{pO}_{2}$ was increased to $100 \mathrm{mmHg}$ immediately after aortic clamping, and normoxic blood cardioplegia was given. $\mathrm{pO}_{2}$ was raised to $\sim 400 \mathrm{mmHg}$ after aortic unclamping.

Mean blood pressure was adjusted to $60-70 \mathrm{mmHg}$ after cardiac contraction resumed. Piglets were observed for $30 \mathrm{~min}$ after CPB, while arterial blood gases and electrolytes were restored to normal levels. Final measurements of biochemical variables and contractile function were made $30 \mathrm{~min}$ after CPB. Hearts were then arrested with cold $\left(4^{\circ} \mathrm{C}\right)$ blood cardioplegia $(\mathrm{KCl} 30 \mathrm{mEq} / \mathrm{l})$ to stop metabolism and a transmural left ventricular biopsy obtained $(\sim 200 \mathrm{mg})$. The subendocardial portion was separated, frozen quickly in liquid nitrogen, and stored for biochemical analyses.

\section{Physiologic and biochemical determinations}

Hemodynamic measurements were made before starting hypoxia (control), every 15 min during hypoxia, and 15 and 30 min after discontinuing CPB. Cardiac output was determined by duplicate injections of $1 \mathrm{ml}$ of $4^{\circ} \mathrm{C}$ cold saline into a central venous catheter. Cardiac index $(\mathrm{CI})$, systemic vascular resistance index (SVRI), pulmonary vascular resistance index (PVRI), and left ventricular stroke work index (LV SWI) were calculated using the following equations:

$$
\begin{aligned}
\mathrm{CI}(\mathrm{ml} / \mathrm{min} / \mathrm{kg}) & =\mathrm{CO} / \text { body weight }(\mathrm{kg}) \\
\text { SVRI }(\text { dyn s cm } & -\mathrm{kg})=(\text { MAP-CVP }) / \mathrm{CO} \\
\text { PVRI }(\text { dyn s cm } & \\
& \times \text { body weight }(\mathrm{kg}) \times 1,000 \\
\text { LVSWI }(\mathrm{g} \cdot \mathrm{m})= & (\text { PAP-LAP }) / \mathrm{CO} \quad \times \text { body weight }(\mathrm{kg}) \times 1,000 \\
& \times 0.0136 /(\mathrm{HR} \times \text { bodyweight }(\mathrm{kg})
\end{aligned}
$$

where MAP is mean aortic pressure, PAP is mean pulmonary artery pressure, LAP is mean left atrial pressure, CVP is central venous pressure, $\mathrm{CO}$ is cardiac output in $\mathrm{ml} / \mathrm{min}$, and HR is heart rate.

\section{Myocardial performance}

Left ventricular pressure and conductance catheter signals were amplified and digitalized to inscribe left ventricular pressure volume loops after correction for tissue conductance (24). A series of pressure volume loops were generated under varying loading conditions by transient occlusion of the inferior vena cava during a 7-s period of apnea. Measurements were made before hypoxia (control) and $30 \mathrm{~min}$ after discontinuing CPB.

The end-systolic pressure volume relationship (ESPVR) was analyzed using a computer graphics program ("Spectrum") on a 383/33 $\mathrm{mHz}$ IBM PC, and LV performance was determined from the descending slope using linear regression and designated end-systolic elastance (Ees) as described previously (25). Post bypass LV contractility was expressed as percent recovery of prebypass control values (percent Ees). Pre- and post-CPB myocardial function was also evaluated using Starling curves by infusing CPB blood into the IVC at $5 \mathrm{ml} / \mathrm{kg} / \mathrm{min}$ while recording CO, MAP, and LAP.

\section{Myocardial nitric oxide production}

NO was determined in plasma by re-converting its oxidation end-products, nitrite $\left(\mathrm{NO}_{2}^{-}\right)$and nitrate $\left(\mathrm{NO}_{3}^{-}\right)$, to $\mathrm{NO}$ and measuring chemiluminescence after NO reacts with ozone using a nitrogen oxides analyzer (DASIBI Environmental Corp., Model 2108, Glendale, CA) (26). Blood samples were taken from coronary perfusate (blood cardioplegia) and coronary effluent (coronary sinus blood) to assess arterial-venous difference in NO during induction of blood cardioplegia. Production of NO was measured by the formula; NO production $=\mathrm{CBF} \times \mathrm{V}-\mathrm{A} / 100 \mathrm{~g}$ heart weight, where $\mathrm{A}$ and $\mathrm{V}$ are the respective concentrations of NO measured in the aortic and coronary sinus blood during cardioplegic delivery when the cardioplegic solution was admin- istered at a fixed coronary blood flow rate (CBF), by calibrated roller pump as described under control studies.

\section{Myocardial oxidant injury}

Myocardial conjugated diene production. Additional aliquots of coronary artery perfusate (blood cardioplegia) and coronary venous effluent were sampled to determine conjugated diene production. Samples were centrifuged immediately for $5 \mathrm{~min}$ at $1000 \times g$. Plasma was stored in liquid nitrogen for later measurements. Conjugated dienes were determined spectrophotometrically as described previously(2), and conjugated diene concentration expressed as absorbance (A) at a wavelength of $233 \mathrm{~nm}$. Conjugated diene production was calculated by the following formula; $\mathrm{CBF}(\mathrm{V}-\mathrm{A}) / 100 \mathrm{~g}$ heart weight, where $\mathrm{A}$ and $\mathrm{V}$ are the concentration of conjugated dienes in the blood cardioplegic perfusate and coronary sinus effluent respectively, and CBF (coronary blood flow) is the blood cardioplegic flow rate in $\mathrm{ml} / \mathrm{min}$.

\section{Antioxidant reserve capacity}

The myocardial antioxidant state was assessed by determining in vitro lipid peroxidation in cardiac tissue that was homogenized and incubated with $t$-butyl hydroperoxide ( $t$-BHP) at concentrations varying from 0 to $4 \mathrm{mM}$ for $30 \mathrm{~min}$ at $37^{\circ} \mathrm{C}(27)$. Lipid peroxidation was determined by measuring thiobarbituric acid (TBA) reactive substances spectrophotometrically at $532 \mathrm{~nm}$. A standard curve is run simultaneously and expressed lipid peroxidation as $\mathrm{nM}$ malondealdehyde/gm protein. Protein was measured by the method of Lowry (28).

\section{Statistical analyses}

Data were analyzed with Statview Version 2.0 (Abacus Concepts, Berkeley, CA). Analyses of variance (ANOVA) was used for comparison between groups. Differences were considered significant at $P$ $<0.05$. Group data are expressed as mean \pm SEM.

\section{Results}

Hemodynamics. The hemodynamic data in control studies and pre- and posthypoxic data in experimental studies are summarized in Table II.

Hypoxemia caused tachycardia (heart rate increased from $170 \pm 10$ to $206 \pm 15$ beats/min), pulmonary vasoconstriction (PVRI increased $120 \pm 21 \%$ ), peripheral vasodilation (SVRI decreased $34 \pm 12 \%$ ) and an initial increase in cardiac output $(28 \pm 8 \%)$. There was no statistically significant difference in bolus $\mathrm{NaHCO}_{3}$ injections (averaging 1-2/piglet) or duration of hypoxia among the groups (Table II).

All piglets could support the circulation after CPB was discontinued, achieving normal to near normal cardiac output after volume infusion. A higher LAP was needed, however, to maintain the same LV stroke work index in piglets receiving uncontrol reoxygenation (Fig. $1 a$ ), and no further augmentation of stroke work index was achieved by volume infusion after LAP exceeded $8-10 \mathrm{mmHg}$.

\section{$L V$ contractility}

Reoxygenation on CPB without surgical ischemia. Reoxygenation with abrupt hyperoxic $\mathrm{pO}_{2}(\sim 400 \mathrm{mmHg})$ in the CPB circuit without superimposed ischemia (aortic crossclamp) was associated with only $25 \pm 5 \%$ recovery of Ees. Fig. $1 b$ shows the pressure volume relationships in a piglet undergoing abrupt reoxygenation on $\mathrm{CPB}$, and Fig. 2 shows the percent recovery of $E_{e s}$ in all studies of reoxygenation without surgical ischemia. Gradual reoxygenation performed by raising $\mathrm{pO}_{2}$ from 25 to $400 \mathrm{mmHg}$ over $1 \mathrm{~h}$ reduced post-CPB myocardial dysfunction minimally, as Ees recovered to $34 \pm 4 \%$ of control.

Reoxygenation on CPB with surgical ischemia. In control studies, myocardial performance was unaffected by the surgical 


\begin{tabular}{|c|c|c|c|c|c|c|c|c|c|}
\hline & \multirow{2}{*}{$\begin{array}{l}\text { Duration of } \\
\text { hypoxia }\end{array}$} & \multicolumn{2}{|c|}{ HR } & \multicolumn{2}{|c|}{$\mathrm{CI}$} & \multicolumn{2}{|c|}{ SVRI } & \multicolumn{2}{|c|}{ Ees } \\
\hline & & pre & post & pre & post & pre & post & pre & post \\
\hline & $\min$ & \multicolumn{2}{|c|}{ beats/min } & \multicolumn{2}{|c|}{$\mathrm{ml} / \mathrm{kg} / \mathrm{min}$} & \multicolumn{2}{|c|}{$d y n / s / \mathrm{cm}^{-5} \mathrm{~kg}$} & \multicolumn{2}{|c|}{$m m H g / m l$} \\
\hline \multicolumn{10}{|l|}{ Control } \\
\hline Control (no CPB) & None & $153 \pm 9$ & $166 \pm 9$ & $99 \pm 8$ & $101 \pm 7$ & $690 \pm 91$ & $724 \pm 89$ & $34.8 \pm 9.9$ & $33.9 \pm 9.0$ \\
\hline BCP (no hypoxia) & None & $160 \pm 17$ & $173 \pm 15$ & $104 \pm 19$ & $94 \pm 11$ & $634 \pm 84$ & $829 \pm 55$ & $32.8 \pm 6.8$ & $32.0 \pm 2.0$ \\
\hline \multicolumn{10}{|l|}{ Hypoxia/reoxygenation } \\
\hline Abrupt reox & $82 \pm 25$ & $170 \pm 8$ & $163 \pm 8$ & $120 \pm 10$ & $69 \pm 7^{*}$ & $617 \pm 43$ & $764 \pm 64$ & $35.0 \pm 12$ & $7.8 \pm 3.2^{* \neq}$ \\
\hline Gradual reox & $69 \pm 22$ & $165 \pm 10$ & $173 \pm 15$ & $112 \pm 15$ & $81 \pm 20$ & $555 \pm 82$ & $513 \pm 82$ & $30.8 \pm 5.7$ & $11.8 \pm 2.8^{* \pm}$ \\
\hline \multicolumn{10}{|c|}{$\begin{array}{l}\text { Hypoxia/reoxygenation with } \\
\text { ischemia }\end{array}$} \\
\hline Initial hyperoxic CPB & $73 \pm 24$ & $168 \pm 6$ & $188 \pm 24$ & $114 \pm 6$ & $63 \pm 17^{*}$ & $527 \pm 52$ & $596 \pm 68$ & $34.8 \pm 9.5$ & $7.7 \pm 2.1^{* \neq}$ \\
\hline Initial normoxic CPB & $77 \pm 30$ & $162 \pm 10$ & $184 \pm 16$ & $115 \pm 15$ & $82 \pm 5^{*}$ & $559 \pm 82$ & $715 \pm 89$ & $30.2 \pm 6.9$ & $15.6 \pm 2.4^{*}$ \\
\hline Initial hypoxic CPB & $83 \pm 27$ & $174 \pm 13$ & $172 \pm 20$ & $110 \pm 10$ & $88 \pm 14$ & $544 \pm 41$ & $589 \pm 38$ & $32.7 \pm 3.8$ & $27.8 \pm 4.7^{\S}$ \\
\hline
\end{tabular}

Pre, control interval; Post, end of study period; $H R$, heart rate; $C I$, cardiac index; $S V R I$, systemic vascular resistance index. ${ }^{*} P<0.05$ vs pre values. ${ }^{\ddagger} P<0.05$ vs Control and BCP. ${ }^{\S} P<0.05$ vs Initial Hyperoxic and Normoxic.

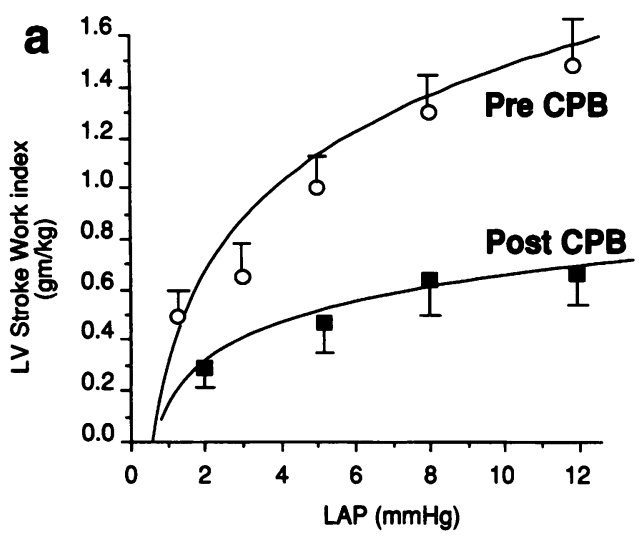

Control

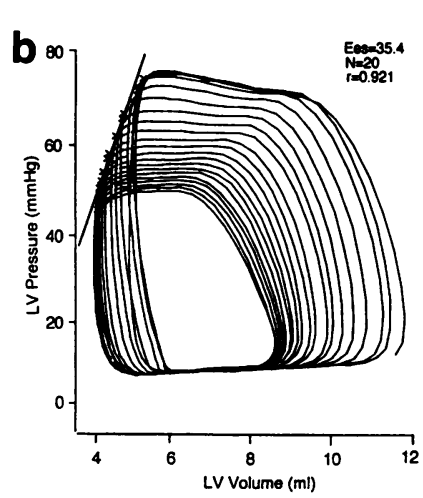

Figure 1. (a) Left ventricular performance assessed by volume loading (Starling curves) before ( 0 ) and after ( $\square$ ) CPB in piglets reoxygenated at $\mathrm{pO}_{2} \sim 400 \mathrm{mmHg}$. These piglets did not undergo surgical ischemia with blood cardioplegia. Note left ventricular $(L V)$ normal stroke work index averages $0.5 \pm 0.06 \mathrm{gm} / \mathrm{kg}$ before inscription of function curves, and failure to increase LV stroke work index as flling pressure is increased after reoxygenation on CPB. Values are mean \pm SE. $(b)$ Pressure volume loops during control interval, before hypoxemia, and after reoxygenation in untreated piglets undergoing abrupt reoxygenation on cardiopulmonary bypass. preparation per se, and in non-hypoxemic piglets undergoing 30 min of aortic clamping with blood cardioplegia also recovered completely. In contrast, initial hyperoxic reoxygenation of hypoxic piglets undergoing this blood cardioplegic regimen was associated with the same level of severe myocardial depression (Ees recovered $21 \pm 2 \%$ ) as hyperoxic reoxygenation without surgical ischemia (Figs. 2 and 3). Conversely, lowering $\mathrm{pO}_{2}$ at the onset of CPB allowed substantial recovery of LV contractility in a $\mathrm{pO}_{2}$-dependent fashion when used in conjunction with blood cardioplegia; percent Ees recovered $56 \pm 10 \%$ with initial normoxemic CPB and was $83 \pm 3 \%$ of control if CPB was started with hypoxic $\mathrm{pO}_{2}$ and reoxygenation was initiated with normoxemic blood cardioplegia (Fig. 3).

\section{Biochemical}

Nitric oxide. NO production was not measured in piglets undergoing abrupt and gradual reoxygenation because coronary

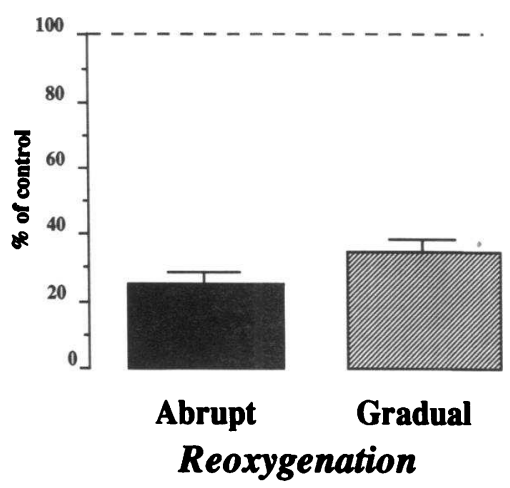

Figure 2. Left ventricular contractility after reoxygenation on cardiopulmonary bypass. Left ventricular Ees after discontinuing CPB is expressed as percent control (ש). Values were obtained after instrumentation, but before hypoxia and CPB. Histograms represent abrupt reoxygenation $\left(\mathrm{ReO}_{2}\right)=\mathrm{pO}_{2} \sim 400 \mathrm{mmHg}$ and gradual $\mathrm{ReO}_{2}=\mathrm{pO}_{2}$ $\sim 25 \mathrm{mmHg}$ that was increased to $400 \mathrm{mmHg}$ over $1 \mathrm{~h}$ of CPB, respectively. These piglets did not undergo surgical ischemia with blood cardioplegia. Note: comparable decrease of contractility after abrupt ( $\square)$ and gradual ( $\square$ ) reoxygenation. 


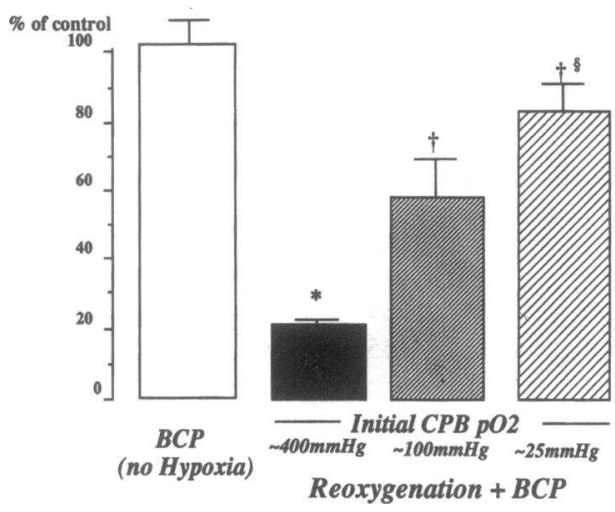

Figure 3. Myocardial contractility (Ees) expressed as percent control values before hypoxia or CPB. $B C P$, blood cardioplegia. The $\mathrm{pO}_{2}$ values reflect the $\mathrm{pO}_{2}$ in the extracorporeal circuit when CPB was started. Note: normal recovery of contractility in control piglets receiving $\mathrm{BCP}$ without preceding hypoxemia ( $\square$ ), and inverse relationship between $\mathrm{pO}_{2}$ during initiating of $\mathrm{CPB}$ when initial $\mathrm{pO}_{2}$ was hyperoxic $\left(\mathrm{pO}_{2} \sim 400 \mathrm{mmHg}\right.$ ), normoxic $\left(\mathrm{pO}_{2} \sim 100 \mathrm{mmHg}\right.$, $\left.\bullet\right)$, or hypoxic ( $\mathrm{pO}_{2} \sim 25 \mathrm{mmHg}$, a) ${ }^{*} P<0.05$ vs. control piglets undergoing $\mathrm{CPB}$ and $\mathrm{BCP}$ without preceding hypoxemia, ${ }^{\dagger} P<0.05$ vs. $\mathrm{pO}_{2}$ $400 \mathrm{mmHg},{ }^{8} P<0.05$ vs. $\mathrm{pO}_{2}=100 \mathrm{mmHg}$.

blood flow could not be measured without the aorta being clamped for cardioplegic delivery. Hyperoxic reoxygenation $\left(\mathrm{pO}_{2}>400 \mathrm{mmHg}\right)$ on CPB was associated with an 11-fold increase in NO production during cardioplegic induction compared to control piglets given the same hyperoxic blood cardioplegic solution. In contrast, this marked NO production was reduced by 70 and $94 \%$, respectively, by controlling cardiac reoxygenation by $(a)$ initiating $\mathrm{CPB}$ at normoxemic levels $\left(\mathrm{pO}_{2} \sim 100 \mathrm{mmHg}\right)$ or $(b)$ starting CPB at ambient hypoxic $\mathrm{pO}_{2}(\sim 25 \mathrm{mmHg})$ and delaying reoxygenation until normoxemic blood cardioplegia was given $\left(\mathrm{pO}_{2} \sim 100 \mathrm{mmHg}\right)$ (Fig. 4).

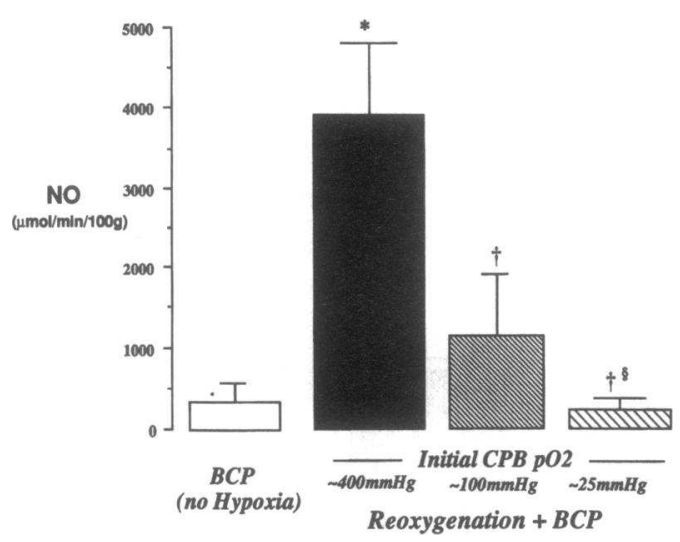

Figure 4. Myocardial nitric oxide production (M/min/100 g heart weight) during $B C P$ induction in control piglets (no hypoxemia), and hypoxemic piglets reoxygenated on CPB with circuit primed at hyperoxic, normoxic and hypoxic $\mathrm{pO}_{2}$ before undergoing surgical ischemia with BCP. Note negligible NO production in control piglets receiving $B C P$ without preceding hypoxemia ( $\square$ ), and direct relationship between $\mathrm{pO}_{2}$ at start of CPB and NO production during induction of blood cardioplegia when initial $\mathrm{pO}_{2}$ was hyperoxic, normoxic, or hypoxic. ${ }^{*} P<0.05$ vs. control piglets undergoing $\mathrm{CPB}$ and $\mathrm{BCP}$ without preceding hypoxemia, ${ }^{\dagger} P<0.05$ vs. $\mathrm{pO}_{2} 400 \mathrm{mmHg},{ }^{8} P$ $<0.05$ vs. $\mathrm{pO}_{2}=100 \mathrm{mmHg}$.

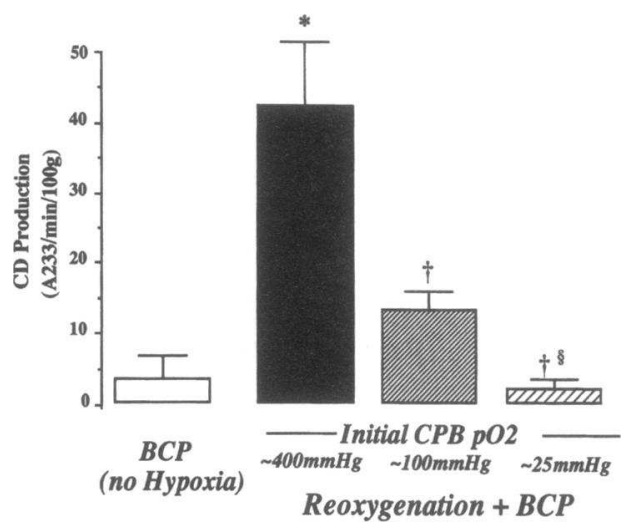

Figure 5. Myocardial conjugated diene $(C D)$ production $\left(\mathrm{A}_{233} / \mathrm{min} /\right.$ $100 \mathrm{~g}$ heart weight) during BCP induction in control piglets (no hypoxemia), and hypoxemic piglets reoxygenated on cardiopulmonary bypass with the circuit primed at hyperoxic; normoxic, and hypoxic $\mathrm{pO}_{2}$ before undergoing surgical ischemia with $\mathrm{BCP}$. Note negligible $\mathrm{CD}$ production in control piglets receiving $\mathrm{BCP}$ without preceding hypoxemia (), and direct relationship between $\mathrm{pO}_{2}$ at start of $\mathrm{CPB}$ and $\mathrm{CD}$ production when initial $\mathrm{pO}_{2}$ was hyperoxic normoxic or hypoxic. ${ }^{*} P<0.05$ vs. control piglets undergoing $\mathrm{CPB}$ and $\mathrm{BCP}$ without preceding hypoxemia, ${ }^{\dagger} P<0.05$ vs. $\mathrm{pO}_{2} 400 \mathrm{mmHg},{ }^{8} P$ $<0.05$ vs. $\mathrm{pO}_{2}=100 \mathrm{mmHg}$.

Myocardial conjugated diene production. The increase in conjugated diene production paralleled elevations in NO production (Figs. 4 and 5). Negligible cardiac-conjugated diene production occurred in non-hypoxemic controlled piglets undergoing $30 \mathrm{~min}$ of surgical ischemia with blood cardioplegia, whereas hyperoxic reoxygenation on CPB caused a 10-fold increase in myocardial conjugated diene production during blood cardioplegic induction (Fig. 5). Conversely, controlled cardiac reoxygenation limited conjugated diene production

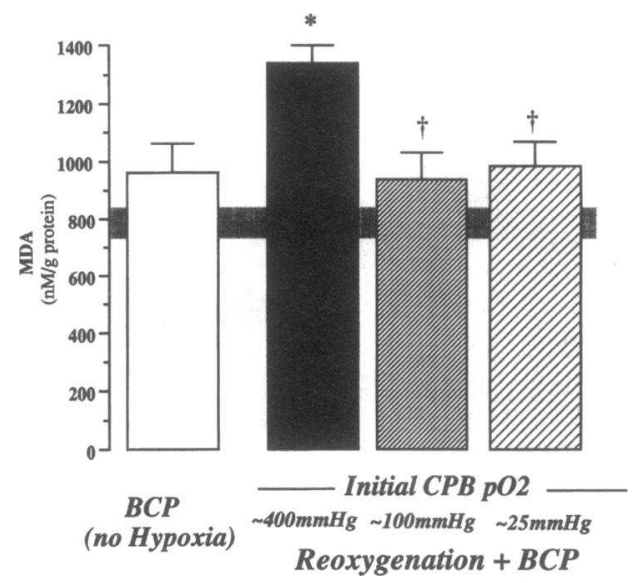

Figure 6. Myocardial antioxidant reserve capacity determined by quantifying malondealdehyde elution (MDA) from myocardial homogenates incubated with the oxidant $t$-butylhydroperoxide ( $t$-BHP) at $4 \mathrm{mM}$ concentration. Hatched area shows range of control values in piglets that were instrumented, but did not undergo either CPB or surgical ischemia with BCP. Each bar shows values in piglet that either did not undergo hypoxemia (no hypoxia) or were reoxygenated on CPB with circuit primed with hyperoxic, normoxic or hypoxic blood before undergoing surgical ischemia with BCP. ${ }^{*} P<0.05$ vs. control piglets undergoing $\mathrm{CPB}$ and $\mathrm{BCP}$ without preceding hypoxemia, ${ }^{\dagger} P<0.05$ vs. $\mathrm{pO}_{2} 400 \mathrm{mmHg}$. 
during cardioplegic induction in a $\mathrm{pO}_{2}$-dependent fashion; production was reduced $62 \%$ when $\mathrm{CPB}$ was started at $\mathrm{pO}_{2} \sim 100$ $\mathrm{mmHg}$ and $95 \%$ at $\mathrm{pO}_{2} \sim 25 \mathrm{mmHg}(P<0.05$ vs. hyperoxic CPB).

Antioxidant reserve capacity. Sudden and gradual reoxygenation to $400 \mathrm{mmHg}$ on CPB without surgical ischemia caused a $68 \pm 5 \%$ and $44 \pm 8 \%$ reduction in antioxidant reserve capacity, respectively. A comparable $59 \pm 8 \%$ impairment occurred in piglets subjected to hyperoxic reoxygenation with subsequent surgical ischemia (Fig. 6). In contrast, starting $\mathrm{CPB}$ at either normoxic or ambient hypoxic levels, followed by normoxemic blood cardioplegia in previously hypoxemic piglets limited the impairment in antioxidant reserve capacity (Fig. 6).

\section{Discussion}

This in vivo study shows that abrupt reoxygenation of cyanotic infantile piglets produces post-CPB myocardial mechanical dysfunction that is associated with augmented NO production provided that molecular $\mathrm{O}_{2}$ is reintroduced by the conventional clinical procedure of raising $\mathrm{pO}_{2}$ to $400 \mathrm{mmHg}$ in the extracorporeal circuit. Post-CPB cardiac dysfunction is associated with signs of lipid peroxidation and depletion of myocardial antioxidants. This reoxygenation damage $(a)$ nullifies the cardioprotective effects of a blood cardioplegic solution, and (b) can be limited or prevented by controlled cardiac reoxygenation, whereby CPB is started using either a hypoxic or a normoxic priming fluid and delaying reoxygenation until the heart is given a normoxic cardioplegic solution developed originally for treating reperfusion injury $(3,4)$. The salutary effects of initiating hypoxic CPB seem related to offsetting reoxygenation injury by delaying reintroduction of molecular oxygen until blood cardioplegic induction, since gradual reoxygenation without blood cardioplegia produced only minimal benefits.

Role of NO. Recent in vitro findings confirm that NO may reduce myocardial contractile dysfunction(29), as originally reported in our in vivo reoxygenation study(2). The present report quantifies a substantially greater production of $\mathrm{NO}$ after reoxygenation than our previous report, since we determined actual production rates of nitrite and nitrate, rather than isolated, serum nitrite determinations alone. These data define a direct correlation between NO production during initial reoxygenation blood cardioplegic induction and the extent of oxidant injury based on conjugated diene production. Improved myocardial function and reduced lipid peroxidation was linked to a suppression of NO by controlling the process of cardiac reoxygenation. Potential sources of NO include the endothelium, myocytes, endocardium and mitochondria (18), but this study does not distinguish their relative contribution to the observed damage. The relative roles of individual elements in the blood cardioplegic solution in suppressing NO production is also not examined.

Arginine is the biochemical precursor of NO and is physiologically responsible for endothelial-derived relaxation. Nitric oxide inhibits vascular adherence of neutrophils, perhaps accounting for the salutary effects of $\mathrm{L}$-arginine in the ischemic/ reperfusion model (30), where blood flow is stagnant and neutrophils become adherent during ischemia and activated during reperfusion (31). Conversely, L-arginine accelerates reoxygenation damage in the in vivo hypoxemic model where coronary blood flow is high, and neutrophil adherence is less likely. Clearly, a balance between the physiologic and pathologic effects of nitric oxide must be established. Furthermore, lactate accumulation may down regulate metabolism during ischemia and provide reducing equivalents during reperfusion (32), whereas the high coronary flow during hypoxemia prevents lactate buildup.

NO production during cardioplegic induction in previously hypoxemic piglets paralleled the initial $\mathrm{pO}_{2}$ level in the extracorporeal circuit. These in vivo findings documenting the relationship between $\mathrm{NO}$ and $\mathrm{pO}_{2}$ are consistent with recent in vitro studies showing the $V_{\max }$ of constitutive NO synthase is related to $\mathrm{O}_{2}$ tension (13). We likely underestimated the true burst of NO with reoxygenation, as coronary blood flow was measured only when blood cardioplegia was delivered $5 \mathrm{~min}$ after starting CPB. Despite delayed measurements, NO production increased 11 -fold in previously hypoxemic hearts placed on CPB at $\mathrm{pO}_{2} 400 \mathrm{mmHg}$ where a similar hyperoxic blood cardioplegic formulation did not cause NO production, conjugated diene generation or myocardial dysfunction under control conditions. We speculate that the excess $\mathrm{NO}$ reacts with $\mathrm{O}_{2}^{-}$ and generates the intermediate $\mathrm{OONO}^{-}$which decomposes to generate highly toxic $\mathrm{O}_{2}$ and $\mathrm{N}_{2}$ intermediates that produce lipid peroxidation. Encroachment on antioxidant reserve capacity occurred only in piglets subjected to uncontrolled reoxygenation and increased susceptibility to a subsequent ischemic insult, such as the interval of aortic clamping needed to optimize operating conditions.

The significant increase in nitric oxide content observed in coronary venous blood when the hypoxic heart was abruptly reoxygenated may result in adverse biochemical reactions besides those related to peroxynitrite formation. NItric oxide mediates iron release from ferritin, the protein that stores excess intracellular iron (33). Heme and non-heme-iron proteins may also be a source of iron release by nitric oxide (34). Recent studies demonstrated an 8-9-fold rise in iron content of coronary blood when flow is re-established after myocardial ischemia (35). Mobilized ferrous iron, released by nitric oxide, is thereby available to react with hydrogen peroxide which also increases with cardiac reoxygenation. Thus, nitric oxide may participate in the Haber-Weiss reaction, but by mechanisms that were not previously appreciated. Increased nitric oxide production and free iron release during reoxygenation is consistent with experimental ${ }^{7}$ and clinical ${ }^{18}$ studies showing the importance of deferoxamine, an iron chelator, in preventing reperfusion-related myocardial damage after CPB.

The possibility exists that there is an NO paradox, just like an $\mathrm{O}_{2}(38)$ and calcium paradox (38), whereby a substance responsible for modulating several physiologic functions (i.e., vascular tone, white blood cell and platelet adherence) may become deleterious when produced in high concentrations upon reoxygenation. The confusion over how the same substance can be both salutary and detrimental is resolved by recognizing that substances may have different actions during vs. after reoxygenation.

Role of $\mathrm{pO}_{2}$. Clinically, cardiopulmonary bypass in hypoxemic infants is initiated at high $\mathrm{pO}_{2}(\sim 400 \mathrm{mmHg})$ without consideration of the possible cytotoxic effects of abrupt reoxygenation. The current study shows that a brief (i.e., $5 \mathrm{~min}$ ) interval of uncontrolled reoxygenation during initial hyperoxic CPB produced sufficient reoxygenation injury to nullify the benefits of blood cardioplegia.

Free radical generation and subsequent myocardial injury 
after reoxygenation are proportionate to oxygen tension (14, $38,39)$. Unfortunately, gradual reoxygenation alone reduced damage only marginally if unaccompanied by blood cardioplegia. We suspect that delaying reoxygenation avoided the burst of $\mathrm{NO}$ and $\mathrm{O}_{2}^{-}$associated with abrupt reoxygenation, since initiating CPB at a hypoxic $\mathrm{pO}_{2}(\sim 25 \mathrm{mmHg})$ followed by reoxygenation with normoxic blood cardioplegia resulted in negligible NO production, avoided lipid peroxidation, and preserved antioxidant reserve capacity. The $\mathrm{pO}_{2}$-dependent nature of this reoxygenation injury was evident from the findings where intermediate results followed initiation of normoxic $\mathrm{CPB}$ at $\mathrm{pO}_{2}$ of approximately $100 \mathrm{mmHg}$ (Figs. 3-5).

Controlled cardiac reoxygenation with blood cardioplegia. Our findings documenting near complete functional recovery after controlled cardiac reoxygenation are consistent with previous observations where controlled reperfusion was used after regional and global ischemia $(4,40,41)$. In addition to the benefits of regulating $\mathrm{pO}_{2}$ when $\mathrm{CPB}$ was initiated, we speculate that several aspects of controlled cardiac reoxygenation with blood cardioplegia limited reoxygenation damage as enumerated previously $(3,4)$ and by some recently defined mechanisms described below.

Normothermic potassium arrest with hypocalcemic, alkalotic blood. The importance of initiating reoxygenation in the normothermically arrested state is underscored by the finding that reoxygenation hypercontraction and sarcolemmal disruption can be prevented by temporary contractile blockade (42). This suggests that some of the limited energy produced during initial reoxygenation is used to normalize cytosolic $\mathrm{Ca}^{2+}$, presumably by improving $\mathrm{Na}^{+}-\mathrm{Ca}^{2+}$ exchange (43). Recent studies link reoxygenation to intracellular calcium loading and membrane damage (44). Hypocalcemia may also limit activation of phospholipases which degrade membrane phospholipids, and lower release of reactive oxygen intermediates via the arachidonic acid and xanthine oxidase pathways (45). It is known now that constitutive NO synthase is $\mathrm{Ca}^{2+} /$ calmodulin dependent, so that decreasing extracellular $\mathrm{Ca}^{2+}$ would attenuate activation of both endothelial and endocardial NO synthase and reduce NO production (18). Reperfusion alkalosis also favors inactivation of $\mathrm{NO}$ by catalyzing its oxidation to inorganic nitrate, as $\mathrm{NO}$ is most stable at acidotic $\mathrm{pH}$ (17).

Glutamate/aspartate supplementation. Both hypoxia and ischemia deplete cytosolic concentrations of the key precursors of Krebs cycle intermediates, glutamate and aspartate; thus, reducing their availability for optimal tricarboxylic acid (TCA) function upon reoxygenation. We showed previously that their replenishment either intravenously or in the cardioplegic solution (3) in hypoxemic or ischemic hearts restored near normal post-ischemic function, presumably via improved energy metabolism. Glutamate and aspartate may also affect the L-arginine-NO-pathway via their conversion to glutamine. Arginine uptake is essential for NO synthesis (46), and is regulated by the cationic amino acid transport system that can be inhibited by L-glutamine and neutral amino acids (19). Glutamine synthetase, present in cardiac muscle, converts glutamic acid to L-glutamine (20), and L-glutamine is synthesized also from aspartate via aspartate aminotransferase (21). In addition to their effect on cardiac energy metabolism, these observations imply that glutamate and aspartate via their conversion to $\mathrm{L}$ glutamine may inhibit L-arginine transport and subsequent NO production.

Reduced reperfusion pressure. Reducing coronary artery pressure during reperfusion improves endothelial-dependent function (47). This was ascribed initially to a reduction in mechanical damage to vulnerable endothelial cells, but endothelium-derived NO is linked closely to sheer stress (22), so that decreasing sheer stress by gentle reperfusion may limit the NO that is generated.

$\mathrm{pO}_{2}$ in blood cardioplegia. Although lowering $\mathrm{pO}_{2}$ in the CPB circuit had negligible effect on reducing reoxygenation injury without blood cardioplegia, $\mathrm{pO}_{2}$ in the blood cardioplegic solution may influence the effectiveness of different factors in the blood cardioplegic strategy, since $\mathrm{O}_{2}^{-}$and $\mathrm{NO}$ production are $\mathrm{pO}_{2}$ dependent $(13,14)$. Hyperoxic blood cardioplegia is probably never needed, since normoxia $\left(\mathrm{pO}_{2} \sim 100 \mathrm{mmHg}\right)$ provides nearly complete $\mathrm{O}_{2}$ saturation and $\mathrm{O}_{2}$ demands are negligible in the arrested decompressed heart (48).

Clinical implications. Our data suggest that an "unintentional" cardiac reoxygenation injury can be produced by the conventional procedure of instituting hyperoxic $\mathrm{CPB}$. This inference is weakened, somewhat, because of the uncertain relevance of the acutely hypoxic model to the patient with chronic cyanosis who develops myocardial metabolic adaptations to hypoxemia (49). The incidence of pre-bypass dysfunction was, however, common to all groups and recovery occurred only in piglets undergoing controlled cardiac reoxygenation.

Our findings are consistent also with observations of patients with chronic cyanosis due to Tetralogy of Fallot who exhibit reduced endogenous antioxidant levels (i.e., glutathione peroxidase, SOD) (50), enhanced vulnerability to oxidant damage (51), and increased conjugated diene production in pre-ischemic myocardial biopsies after conventional CBP is started (6). This myocardial reoxygenation changes may increase vulnerability to subsequent ischemic/reperfusion injury in the surgical setting and contribute to post-bypass cardiac dysfunction, where standard methods of blood cardioplegic protection are less cardioprotective compared with acyanotic adult patients undergoing coronary revascularization despite shorter ischemic intervals (7).

The functional depression quantified by the sensitive indices (Ees) and inscription of ventricular function curves may seem incompatible with the "uneventful" postoperative course after straightforward repair of cyanotic children with pulmonary stenosis or Tetralogy of Fallot. All piglets could be weaned from cardiopulmonary bypass and depressed function was defined by reduced Ees and normal cardiac output at increased filling pressures. This impairment of function may not be appreciated from the bedside where functional reserve is not tested. Our findings may explain why inotropic support is often needed postoperatively in cyanotic children. The occurrence of reoxygenation injury is evident also in cyanotic infants who undergo extracorporeal membrane oxygenation (ECMO) for respiratory failure, as reduced systolic function which progresses to "cardiac stun" occurs despite no surgical ischemia $(8,9)$.

We interpret our data to suggest that altering routine techniques of conventional cardiopulmonary bypass may limit cardiac reoxygenation damage, and that the observed injury may be related to augmented NO production when CPB is started. Initiation of $\mathrm{CPB}$ at hypoxic $\mathrm{pO}_{2}$ reduces $\mathrm{NO}$ production and would likely be safe since the flow in the extracorporeal circuit could be augmented to ensure tissue $\mathrm{O}_{2}$ delivery when bypass is started. Furthermore, normoxic initiation on $\mathrm{CPB}$ at $\mathrm{pO}_{2}$ $\sim 100 \mathrm{mmHg}$ ensures $\sim 99 \%$ oxygen saturation without ad- 
justment of the CPB flow, and it is unlikely that hyperoxic CPB is ever needed in clinical practice, since $\mathrm{pO}_{2}>100-150 \mathrm{mmHg}$ confers only negligible increase in oxygen content. The avoidance of hyperoxia during reoxygenation in cyanotic hearts to reduce reoxygenation injury may, in a sense, be comparable to restricting inspired $\mathrm{FIO}_{2}$ in newborn infants to avoid retrolental fibroplasia (52). The techniques of controlled cardiac reoxygenation used in this study are available in routine practice, and can hopefully be used to limit cardiac reoxygenation injury during repair of congenital defects causing cyanosis.

\section{Acknowledgments}

The authors wish to thank Nanci Stellino and Garland Hodges for technical assistance and Judith Becker for word processing assistance.

This research was supported by National Heart, Lung, and Blood Institute grants HL-40675, and HL-40922, the University of California Tobacco-Related Disease Research program.

\section{References}

1. Allen, B. S., G. D. Buckberg, M. Schwaiger, L. Yeatman, J. Tillisch, N. Kawata, J. Messenger, and C. Lee. 1986. Studies of controlled reperfusion after ischemia. XVI. Early recovery of regional wall motion in patients following surgical revascularization after eight hours of acute coronary occlusion. $J$. Thorac. Cardiovasc. Surg. 92:636-648.

2. Allen, B. S., F. Okamoto, G. D. Buckberg, H. I. Bugyi, H. Young, J. Leaf, F. Beyersdorf, F. Sjostrand, and J. V. Maloney Jr. 1986. Studies of controlled reperfusion after ischemia. XV. Immediate functional recovery after 6 hours of regional ischemia by careful control of conditions of reperfusion and composition of reperfusate. J. Thorac. Cardiovasc. Surg. 92:621-635.

3. Bavaverl, G., G. Martin, and C. Michoudet. 1990. Glutamine synthesis from aspartate in guinea-pig renal cortex. Biochem. J. 268:437-442.

4. Beckman, J. S., T. W. Beckman, J. Chen, P. A. Marshall, and B. A. Freeman. 1990. Apparent hydroxyl radical production by peroxynitrite: Implications for endothelial injury from nitric oxide and superoxide. Proc. Natl. Acad. Sci. USA 87:1620-1624.

5. Bogie, R. G., S. B. Coade, S. Moncada, J. D. Pearson, and G. E. Mann. 1991. Bradykinin and ATP stimulate $L$-arginine uptake and nitric oxide release in vascular endothelial cells. Biophys. Res. Commun. 180:926-932.

6. Bolli, R., M. O. Jeroudi, and B. S. Patel. 1989. Direct evidence that oxygenderived free radicals contribute to postischemic myocardial dysfunction in the intact dog. Proc. Natl. Acad. Sci. USA. 86:4695-4699.

7. Bolli, R., B. S. Patel, M. O. Jeroudi, X. Y. Li, J. F. Triana, E. K. Lai, and P. B. McCay. 1990. Iron-mediated radical reactions upon reperfusion contribute to myocardial "stunning". Am. J. Physiol. 259:H1901-H1911. 8. Brady, A. J. B., P. A. Poole-Wilson, S.E Harding, and J. B. Warren. 1992. Nitric oxide production within cardiac myocytes reduces their contractility in endotoxemia. Am. J. Physiol. 263:H1963-H1966.

9. Buckberg, G. D. 1991. Myocardial temperature management during aortic clamping for cardiac surgery. J. Thorac. Cardiovasc. Surg. 102:895-903.

10. Burton, K. P., A. C. Morris, K. D. Massey, L. M. Buja, and H. K. Hagler. 1990. Free radicals alter ionic calcium levels and membrane phospholipids in cultured rat ventricular myocytes. J. Mol. Cell. Cardiol. 22:1035-1047.

11. Bush, P. A., N. E. Gonzalez, J. M. Griscavage, and L. J. Ignarro. 1992. Nitric oxide synthase from cerebellum catalyzes the formation of equimolar quantities of nitric oxide and citrulline from L-arginine. Biochem. Biophys. Res. Commun. 185:960-966.

12. Chevion, M., Y. Jiang, R. Har-El, E. Berenshtein, G. Uretzky, and N. Kitrossky. 1993. Copper and iron are mobilized following myocardial ischemia: Possible predictive criteria for tissue injury. Proc. Natl. Acad. Sci. USA. 90:11021106.

13. Davies, M. J. 1987. Applications of electron spin resonance spectroscopy to the identification of radicals produced during lipid peroxidation. Chemistry and Physics of Lipids. 44:149-173.

14. Del Nido, P. J., D. A. G. Mickle, G. J. Wilson, L. N. Benson, J. G. Coles, G. A. Trusler, and W. G. Williams. 1987. Evidence of myocardial free radical injury during elective repair of tetralogy of Fallot. Circulation. 76:Suppl V:174 179.

15. Del Nido, P. J., D. A. G. Mickle, G. J. Wilson, L. N. Benson, R. D. Weisel, J. G. Coles, G. A. Trusler, and W. G. Williams. 1988. Inadequate myocardial protection with cold cardioplegic arrest during repair of tetralogy of Fallot. $J$. Thorac. Cardiovasc. Surg. 95:223-229.
16. Drinkwater, D. C.Jr., C. K. Cushen, H. Laks, and G. D. Buckberg. 1992. The use of combined antegrade-retrograde infusion of blood cardioplegic solution in pediatric patients undergoing heart operation. J. Thorac. Cardiovasc. Surg. 104:1349-1355.

17. Engler, R. L., G. W. Schmid-Schonbein, and R. S. Pavelec. 1983. Leukocyte capillary plugging in myocardial ischemia and reperfusion in the dog. Am.J. Pathol. 111:98-111.

18. Ferreira, R., M. Burgos, J. Milei, S. Llesuy, L. Molteni, H. Hourquebie, and A. Boveris. 1990. Effect of supplementing cardioplegic solution with deferoxamine on reperfused human myocardium. J. Thorac. Cardiovasc. Surg. 100:708-714.

19. Gauduel, Y., P. Menasche, and M. Duvelleroy. 1989. Enzyme release and mitochondrial activity in reoxygenated cardiac muscle: Relationship with oxygen-induced lipid peroxidation. Gen. Physio. Biophys. 8:327-340.

20. Godin, D. V., K. M. Ko, and M. E. Garnett. 1989. Altered antioxidant status in the ischemic/reperfused rabbit myocardim: Effects of allopurinol. Can. J. Cardiol. 5:365-371.

21. Greene, B., A. J. Pacitti, and W. W. Souba. 1993. Characterization of L-arginine transport by pulmonary artery endothelial cells. Am. J. Physiol. 264:L351-360.

22. Guarnieri, C., F. Flamigni, and C. M. Caldarera. 1980. Role of oxygen in the cellular damage induced by reoxygenation of hypoxic heart. J. Mol. Cell. Cardiol. 12:797-808.

23. Halliwell, B. 1992. Reactive oxygen species and the central nervous system. J. Neurochem. 59:1609-1623.

24. Hearse, D. J., S. M. Humphrey, and G. R. Bullock. 1978. The oxygen paradox and the calcium paradox: Two facets of the same problem?. J. Mol. Cell. Cardiol. 10:641-668.

25. Heffner, J. E., and J. E. Repine. 1989. Pulmonary strategies of antioxidant defense. Am. Rev. Respir. Dis. 140:531-554.

26. Hirschl, R. B., K. F. Heiss, and R. H. Bartlett. 1992. Severe myocardial dysfunction during extracorporeal membrane oxygenation. J. Pediatr. Surg. 27:48-53.

27. Ignarro, L. J. 1990. Biosynthesis and metabolism of endothelium-derived nitric oxide. Annu. Rev. Pharmacol. Toxicol. 30:535-560.

28. Jacobson, R. M., and A. R. Feinstein. 1992. Oxygen as a cause of blindness in premature infants: "autopsy" of a decade of errors in clinical epidemiologic research. J. Clin. Epidemiol. 45:1265-1287.

29. Kirklin, J. K., E. H. Blackstone, J. W. Kirklin, R. McKay, A. D. Pacifico, and L. M.Jr. Bargeron. 1981. Intracardiac surgery in infants under age 3 months: Incremental risk factors for hospital mortality. Am. J. Cardiol. 48:500-506.

30. Kowalski, D. P., T. Y. Aw, Y. Park, and D. P. Jones. 1992. Postanoxic oxidative injury in rat hepatocytes: Lactate-dependent protection against tert-butylhydroperoxide. Free Radical Bio. \& Med. 12:205-212.

31. Krivokapich, J., J. R. Barrio, M. E. Phelps, C. R. Watanabe, R. E. Keen, H. C. Padgett, A. Douglas, and K. I. Shine. 1984. Kinetic characterization of $13 \mathrm{NH} 3$ and $13 \mathrm{~N}$ glutamine metabolism in rabbit heart. Am. J. Physiol. 246:H267-H273.

32. Kukreja, R. C., H. A. Kontos, M. L. Hess, and E. F. Ellis. 1986. PGH synthase and lipoxygenase generate superoxide in the presence of NADH or NADPH. Circ. Res. 59:612-619.

33. Lazar, H. L., G. D. Buckberg, A. M. Manganaro, and H. Becker. 1980. Myocardial energy replenishment and reversal of ischemic damage by substrate enhancement of secondary blood cardioplegia with amino acids during reperfusion. J. Thorac. Cardiovasc. Surg. 80:350-359.

34. Li, K., D. A. G. Mickle, R. D. Weisel, L. C. Tumiati, G. Jackowski, T. W. $\mathrm{Wu}$, and W. G. Williams. 1989. Effect of oxygen tension on the anti-oxidan enzyme activities of tetralogy of fallot ventricular myocytes. J. Mol. Cell. Cardiol. 21:567-575.

35. Littauer, A., and H. DeGroot. 1992. Release of reactive oxygen by hepatocytes on reoxygenation: three phases and role of mitochondria. Am. J. Physiol. 262:G1015-1020.

36. Loop, F. D., T. L. Higgins, R. Panda, G. Pearce, and F. G. Estafanous 1992. Myocardial protection during cardiac operations. J. Thorac. Cardiovasc. Surg. 104:608-618.

37. Lowry, O. H., N. J. Rosebrough, A. L. Farr, and R. J. Randall. 1951. Protein measurement with the folin phenol reagent. J. Biol. Chem. 193:265-275.

38. Martin, G. R., B. L. Short, C. Abbott, and A. O'Brien. 1991. Cardiac stun in infants undergoing extracorporeal membrane oxygenation. J. Thorac. Cardiovasc. Surg. 101:607-611.

39. Matheis, G., M. P. Sherman, G. D. Buckberg, D. M. Haybron, H. H. Young, and L. J. Ignarro. 1992. Role of L-arginine-nitric oxide pathway in myocardial reoxygenation injury. Am. J. Physiol. 262:H616-H620.

40. Moncada, S., R. M. J. Palmer, and E. A. Higgs. 1991. Nitric Oxide: Physiology, pathophysiology, and pharmacology. Pharmacol. Rev. 43:109-134.

41. Ohno, M., G. H. Gibbons, V. J. Dzau, and J. P. Cooke. 1993. Shear stress elevates endothelial cGMP. Role of a potassium channel and G Protein Coupling. Circulation 88:193-197.

42. Reif, D. W., and R. D. Simmons. 1990. Nitric oxide mediates iron release from ferritin. Arch. Biochem. Biophys. 283:537-541. 
43. Rengasamy, A., and R. A. Johns. 1991. Characterization of endotheliumderived relaxing factor/nitric oxide synthase from bovine cerebellum and mechanism of modulation by high and low oxygen tensions. J. Pharmacol. Exp. Ther 259:310-316.

44. Rosenkranz, E. R., F. Okamoto, G. D. Buckberg, J. M. Robertson, J. Vinten-Johansen, and H. Bugyi. 1986. Safety of prolonged aortic clamping with blood cardioplegia. III. Aspartate enrichment of glutamate-blood cardioplegia in energy-depelted hearts after ischemic and reperfusion injury. J. Thorac. Cardio vasc. Surg. 91:428-435.

45. Rudolph, W. 1971. Myocardial metabolism in cyanotic congenital heart disease. Cardiology. 56:209-215.

46. Sagawa, K. 1978. The ventricular pressure-volume diagram revisited. Circ. Res. 43:677-687.

47. Sawatari, K., K. Kadoba, K. A. Bergner, and J. E. Mayer, Jr. 1991. Influence of initial reperfusion pressure after hypothermic cardioplegic ischemia on endothelial modulation of coronary tone in neonatal lambs. J. Thorac. Cardio vasc. Surg. 101:777-782.
48. Schluter, K. D., P. Schwartz, B. Siegmund, and H. M. Piper. 1991. Prevention of the oxygen paradox in hypoxic-reoxygenated hearts. Am. J. Physiol. 261:H416-423.

49. Tani, M., and J. R. Neely. 1990. Mechanisms of reduced reperfusion injury by low $\mathrm{Ca}^{++}$and/or high $\mathrm{K}^{+}$. Am. J. Physiol. 258:H1025-H1031.

50. Teitel, D. F., R. Klautz, P. Steenduk, E. T. Van der Velde, F. Van Bel, and J. Baan. 1991. The endo-systolic pressure-volume relationship in the newborn lamb: Effects of loading and inotropic interventions. Pediatr. Res. 29:473-482.

51. Teoh, K. H., D. A. G. Mickle, R. D. Weisel, R. Li, L. C. Tumiati, J. G. Coles, and W. G. Williams. 1992. Effect of oxygen tension and cardiovascular operations on the myocardial antioxidant enzyme activities in patients with tetralogy of Fallot and aorta-coronary bypass. J. Thorac. Cardiovasc. Surg. 104:159164.

52. Weyrich, A. S., X. Ma, and A. M. Lefer. 1992. The role of L-arginine in amerliorating reperfusion injury after myocardial ischemia in the cat. Circula tion. 86:279-288. 